\title{
A typological study of Public Open Space in Private Developments in Hong Kong
}

Izzy Yi JIAN, Department of Building and Real Estate, and Research Institute for Sustainable Urban Development, The Hong Kong Polytechnic University, Hong Kong SAR

Esther H.K YUNG, Department of Building and Real Estate, The Hong Kong Polytechnic University, Hong Kong SAR

May Jiemei LUO, Department of Building and Real Estate, and Research Institute for Sustainable Urban Development, The Hong Kong Polytechnic University, Hong Kong SAR; and College of Architecture and Urban Planning, University of Tongji University, Shanghai, China

Edwin H.W. CHAN, Department of Building and Real Estate, and Research Institute for Sustainable Urban Development, The Hong Kong Polytechnic University, Hong Kong SAR

Weizhen CHEN, College of Architecture and Urban Planning, University of Tongji University, Shanghai, China

\begin{abstract}
Public Open Space (POS) can generate a range of benefits across economic, social and environmental dimensions. As the government gradually contracting out the urban development responsibilities to private sectors, the fundamental mechanisms for the provision and management of POS have altered in cities all over the world. Public Open Space in Private Developments (POSPD) are accused of limiting the manifestation of social or ethnic identity, declining in public space quality. The typological study of POSPD offers a vital tool to understand, assessing and improving the existing POSPD. However, there are surprisingly few published typologies investigating the publicness and management dimension with a special focus on POSPD. Intentionally, we first discuss existing classifications and typologies of POS and comply with a list of complex measures that are inherited from scholars' previous research. By examining the diversity of POSPD in terms of its spatial justice performance, we organise this diversity into a POSPD typology dedicated to compact urban morphology. The proposed POSPD typology allows the most effective management of existing POSPD, as well as a more precise recognition of gaps that is relevant to $P O S$ service and governance practice.
\end{abstract}

\section{Keywords}

Public Open Space, Spatial Justice, Publicness, Management, Typology

\section{Introduction}

While "private" often refers to the sphere conserved from state power and a share of an individual's life, "public" is generally associated with collective goals (Mantey and Kępkowicz, 2018). Public Open Space (POS) is capable of generating a range of benefits across economic, social and environmental dimensions (Carmona, 2010). Public Open Space in Private Developments (POSPD) can increase the amount of urban POS effectively. Yet, this merit is often accompanied by the implementation of strict control and surveillance within these spaces. POSPD are accused of limiting the manifestation of social or ethnic identity, declining in public space quality (Mantey and Kępkowicz, 2018). Creating POSPD with restrained accessibility across a city may aggravate instead of promoting spatial justice (Carmona, 2010). 
POSPD differ dramatically in their physical characteristics and social roles. The typological study of POSPD offers a vital tool to understand, assessing and improving the existing POSPD. However, there are surprisingly few published typologies investigating the publicness and management dimension with a special focus on POSPD. No synthesis exists in the urban design literature to organise and link these research. This research aims to address this gap. An attempt was made to categorise the existing POSPD in order to propose a new typology.

Intentionally, we first discuss existing classifications and typologies of POS and comply with a list of complex measures that are inherited from scholars' previous research. Under the guidance of a Checklist that measures the spatial attributes that would characterize the benefits of POS as "public," this study conducted field survey of the current status of Hong Kong's POSPD. By examining the diversity of POSPD in terms of its spatial justice performance, publicness and management to be specific, we organise this diversity into a POSPD typology dedicated to compact urban morphology. Two methods were adopted in the categorisation process namely classification and typology. The proposed POSPD typology allows the most effective management of existing POSPD, as well as a more precise recognition of gaps that is relevant to POS service and governance practice. The paper concludes with policy suggestion and future research.

\section{Spatial Justice and Publicness}

The connotation of spatial justice performance of POS express itself from two levels: the neighbourhood level and the site level, with the former stress the urban form of the built environment within the service area of the POS, and the latter emphasise the spatial characteristics of the space itself (Jian et al., 2020b). In this research, we measure the publicness and control of the POS as one of the proxies for circumscribing the nature of spatial justice.

Publicness is a concept that has to do with context (De Magalhães, 2010). Authors all over the world comprehended publicness as a multidimensional character of the space. For a space with "good publicness," it is expected to be accessible, "open-ended and 'loose'," inclusive, to provide venues for diversity users that free from marginalisation and behaviour control, and allow for spontaneity and unprogrammed activities (Young, 1990, Németh and Schmidt, 2011). Attributes highlighted by previous research that constitute the assessment of publicness and control include but not limited to ownership, management/control/actor, intersubjectivity, accessibility, rights of usage/interest, design and image, as well as function and perception (Kohn, 2004, Akkar, 2005, Carmona, 2010, Németh and Schmidt, 2011, Varna and Tiesdell, 2010).

Instead of talking about the legal status and ownership of a POS, this research mainly draws the dimensions of accessibility, management/control, rights of usage, and design and image when assessing the publicness and control of a POS. Notably, the pre-existing evaluation frameworks reached little consensus on which variables can best represent this research issue, and our analysis is based on previous-tested indicators of publicness and control research that also reflect Hong Kong's specific demographic context.

\section{Methodology}

The methodology for the Typological study mainly constitutes two parts: field survey and clustering analysis. This method captures qualitative data via direct-observations and quantitative data gathered by direct-counting on-site with the guidance of a designed checklist. 
In order to efficiently and succinctly examine the relevant built environment of the selected POSPD, we designed a Field Observation \& Checklist based on Hong Kong's Public Open Space in Private Developments Design and Management Guidelines as well as previous research which quantitatively measured the spatial justice performance and publicness of public spaces with an emphasis on the private control over the space (Németh and Schmidt, 2007, Schmidt et al., 2011, Jian et al., 2020b). The final Checklist records the period of field observation, general information of the public space, and scores the physical environment from four aspects, namely Amenity and Facility, Safety, Management and information, and Accessibility. Because of the multiple-level spatial system in Hong Kong, we give special considerations to the visibility and information of the POSPD (Jian et al., 2020a). The four aspects consist of 19 variables. For each variable, we scored it using a code $(0,1,2)$ that corresponds to one environmental condition according to the presence or intensity of a specific item (Németh and Schmidt, 2007, Wang and Chen, 2018). The overall score was attained by summing up the scores of all variables on an arithmetic basis to create a publicness index which ranged from a high of 38 to a low of 0 , a higher score indicates a higher degree of publicness and the encourage of space usage.

Numerous visits to the 66 POSPD were carried out during 2019 and 2020. In total, 61 POSPD in Hong Kong were classified in groups based on the criteria contained in the Checklist. Correlation Analysis was conducted to confirm the variables that are relevant to our research issue (Ho et al., 2020). We then carried out Hierarchical Clustering to potentially group the POSPD into different typologies.

\section{Typology Results}

Overall, the results generate five clusters, with each POSPD being classified into an appropriate group. The detail information of each cluster is presented as follows.

\section{Cluster 1, "Edge Zone”}

\section{Poor facility provision}

Cluster 1 includes 12 POSPD. Cases of this cluster provide limited facility and amenity. These spaces only have basic seats, usually fixed stone bench, and badly designed artificial lights with no art work nor fitness facilities. This may directly constrain the possible activity types that can be carried out in these POSPD.
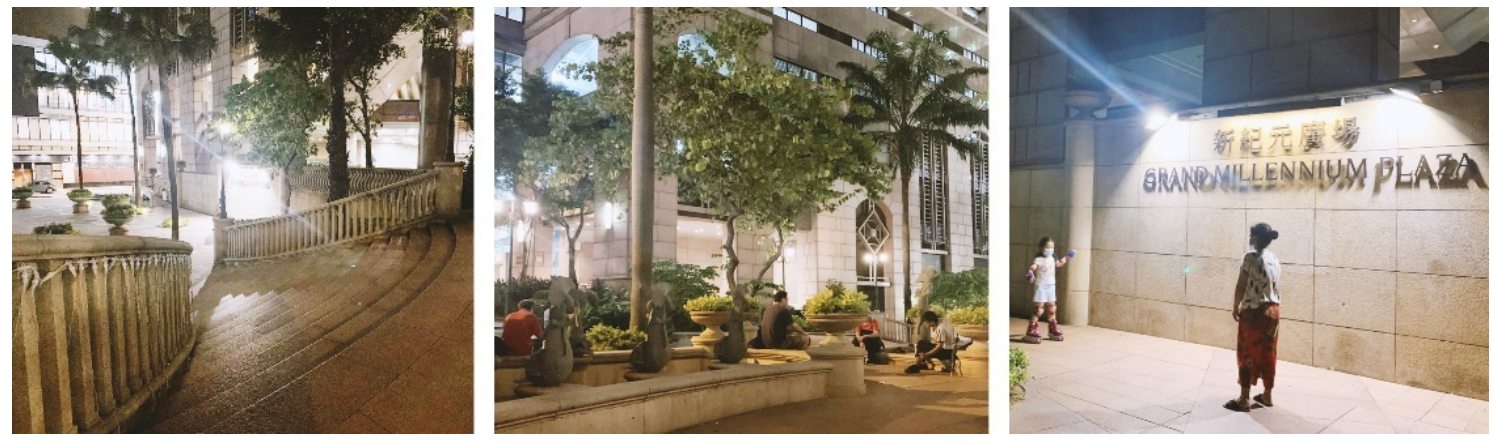

Figure 1 Cosco Tower and Grand Millennium Plaza

Overall, the Cosco Tower and Grand Millennium Plaza scored relatively higher concerning public facilities. This contributes to its overall performance and makes it ranks first in this cluster in terms of the overall score (Figure 1). The Plaza was once recognised as a good POSPD example by The Hong Kong Public Space Initiative $^{1}$ (HKPSI) when assessed from the aspects of accessibility, environment and facilities, public

1 http://www.hkpsi.org/eng/main/ 
utilisation and sociability. However, they also pointed out that this POSPD lacked activity support. Their report entitled this POSPD as "a smoking area" (Initiative, 2018). In fact, no specific seats and shelters are provided in this space, people sit along with the spray fountain which is already dry due to lack of maintenance.

\section{Freedom of use}

Cluster 1 can be further divided into two groups in terms of freedom of use. For POSPD in Cluster C1-1, no surveillance from CCTV or security personnel but rules highly visible, with C1-2 almost has no policing nor rules posted to limit people's freedom of use. The spaces are largely developed without commercialising. No area is restricted in this type, with most of the cases are open to the public 24 hours.

\section{Average Maintenance}

Cluster One has a mediocre performance for "Litter/ graffiti/ freeway noise/ overgrown vegetable". The POSPD is either unsanitary or a wilderness of grass and weeds, or has a high level of traffic noise.

\section{Good Accessibility}

Despite the poor space quality, this cluster presents high visual and spatial accessibility. The POSPD of Heya Aqua offers a good example. The tiny pocket space is located at the ground level, surrounded by decrepit residential buildings. It is poorly designed with excessive hard cover and exiguous flora. Yet, it is directly front the street side. People can see it directly from the street (Figure 2).
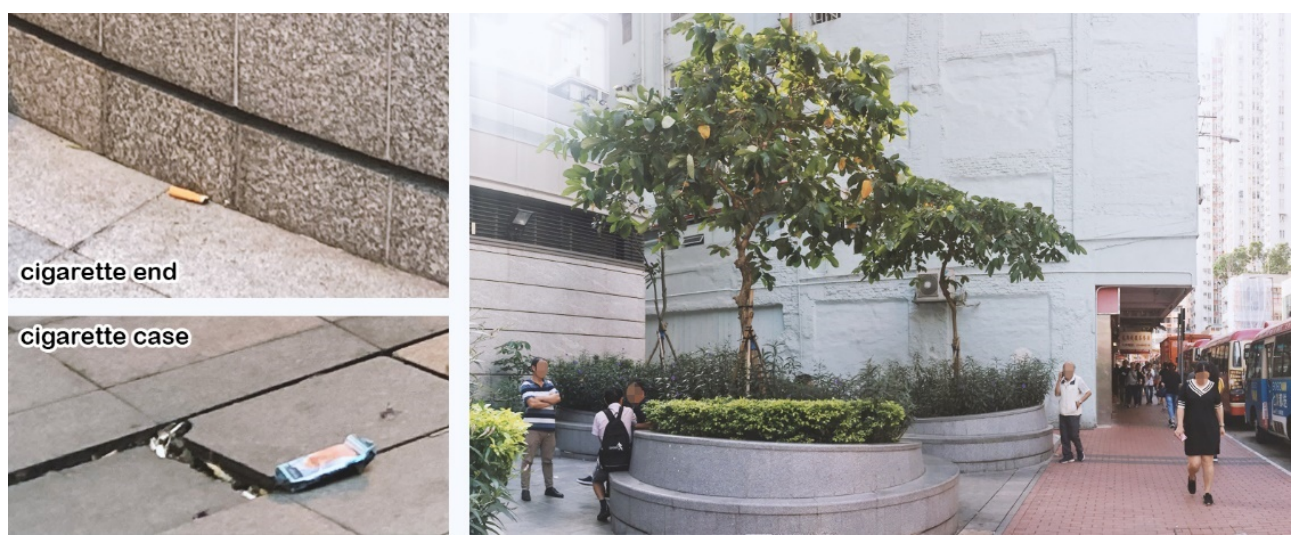

Figure 2 Heya Aqua's maintenance (left) and accessibility (right)

\section{Cluster 2, "Hide-and-Seek"}

\section{Poor facility provision}

Generally speaking, cases of Cluster 2 have lower scores compared to other cases. Most cases do poorly in maintenance and sanitation. Similar to Cluster One, POSPD in cluster 2 is constrained by its poor facility provision. Only The Centrium located in Central and Western district got a good score in terms of available shelter, diverse seating type and the provision of both planning and water feature. Yet, part of this POSPD "hides itself" because no artificial light provided during the night (Figure 3). 

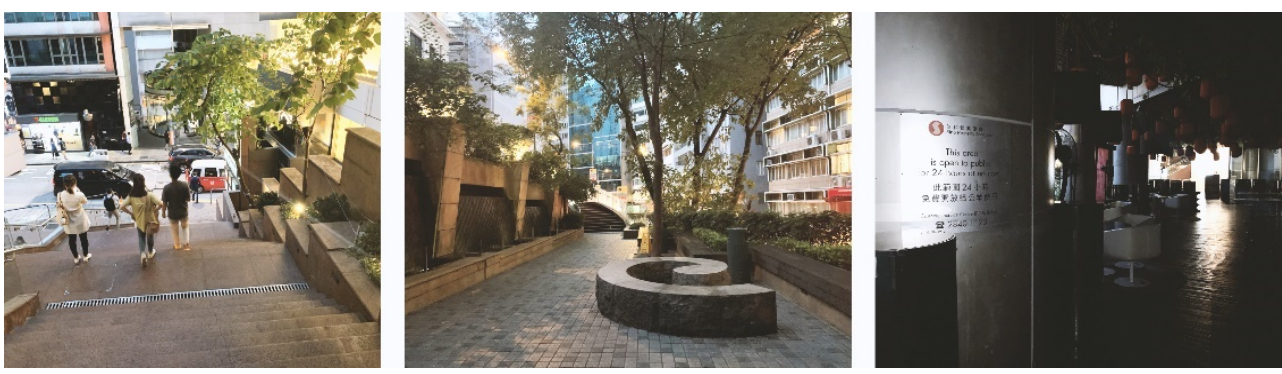

Figure $\mathbf{3}$ The Centrium, with the signage in the right picture indicating "This area is open to public for 24 hours at no cost."

\section{Invisible Space}

Yet, the 15 POSPD in Cluster 2 all perform badly in visual and physical access. Some of them are located at the roof level with no indication of their existence and availability. For example, New Kwai Fong Gardens, as well as Sun Kai Hing Gardens, which is very close to the former, are roof terraces of the residential buildings. As revealed by local media, despite the POSPD of New Kwai Fong Gardens has been completed in 1983, the space is more like a private garden instead of a public space (Mingzi, 2019). Similarly, Hollywood Terrace, which is attached to a residential development and named "Landscape Garden" by the developer, is not connected to pedestrian flows (Rossini and Yiu, 2020). As stated by the notice, the lift service is "not opened to the public and only be exclusively used by our residents." The general public must claim many steps to reach the space (Figure 4).
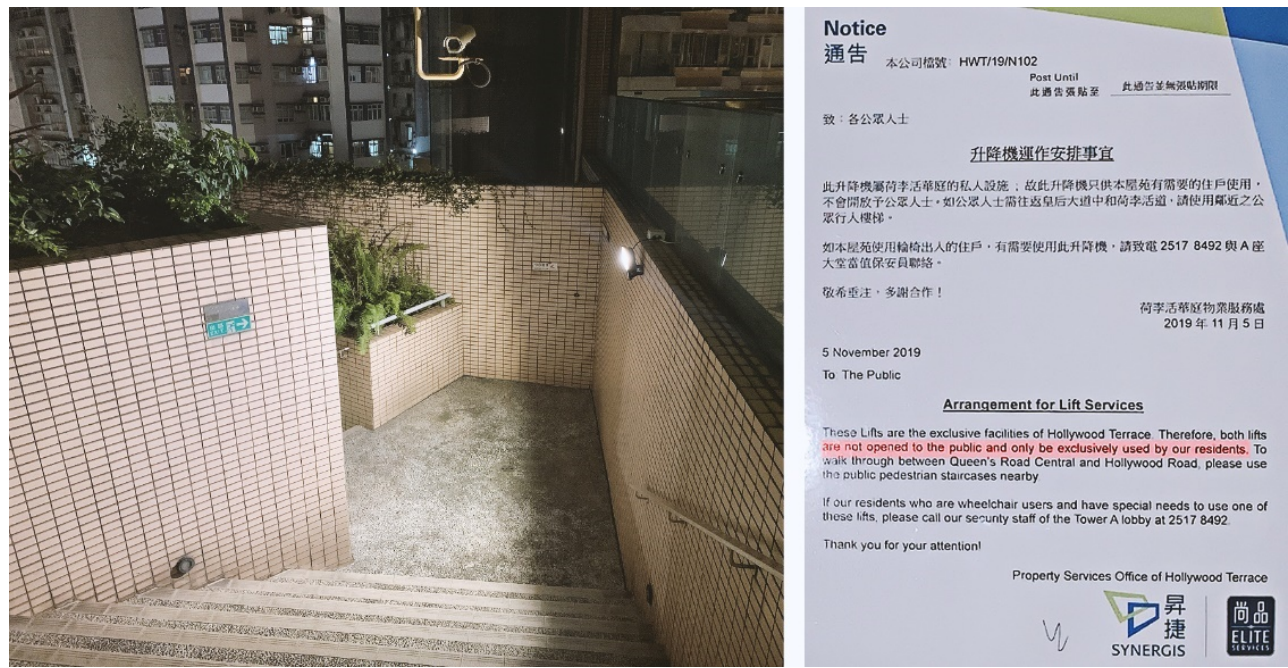

Figure 4 Hollywood Terrace and it's Notice

\section{Neglected Corner}

The Portofino in Sai Kung district is an extreme case of Cluster 2. Both "stand out" as neglected spaces and have overall scores of 14 and 16, respectively (Carmona, 2010). The Portofino is an expensive gated community with many social celebrities living in these mansions. The community is in a beautiful situation and well maintained by the property managers. However, the POSPD developed by which have poor performance in its location, quality and maintenance. For this hiking trail, trees were to be left uncut, roads were uncleaned with fallen leaves. Despite that, the place is under 24-hour monitoring (Figure 5). 

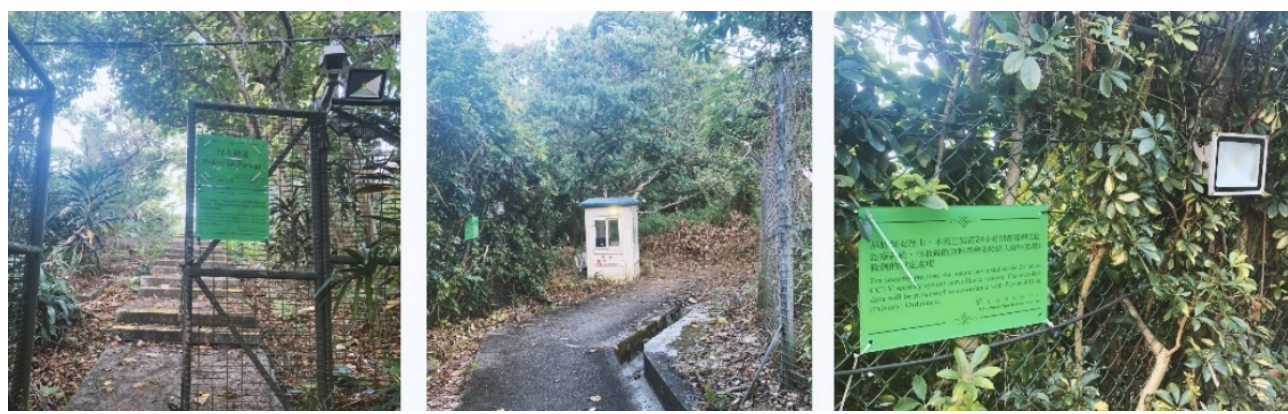

Figure 5 The Portofino's POSPD

\section{Cluster 3, "Pseudo-Public Park"}

\section{Clear public status}

Cluster 3 consists of 14 spaces. Generally, all POSPD in this Cluster are well advertised as "public open space" with opening hour clearly presented (Figure 6).

\section{High space quality}

Spaces consist of Cluster 3 may have different characteristics, but all of them are of good spatial quality with meticulous design. For instance, Cheung Kong Park, which is the POSPD attached to Cheung Kong Centre, is a city park in the concrete jungles that features a wide variety of trees and canopies. It provides a green environment that facilitates rich and diverse flora and fauna. On the other hand, Kowloon Station Development and Hong Kong Station Development, two large complexes developed by MTR Corporation. These two spaces are designed under a more modernised concept with geometric artwork presented (Figure 7). Different types of seats are provided, and the spaces have a delightful sea view of Victoria Harbour.
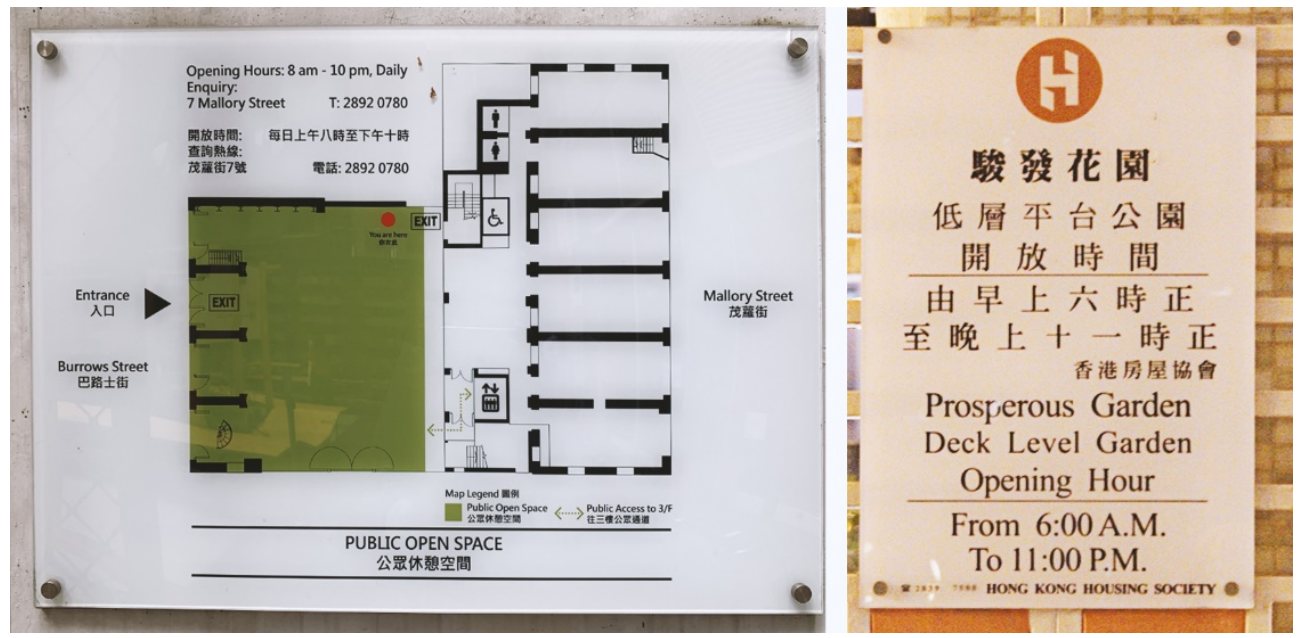

Figure 6 Open Hours of Comix Home Base (left) and Prosperous Garden (right) 

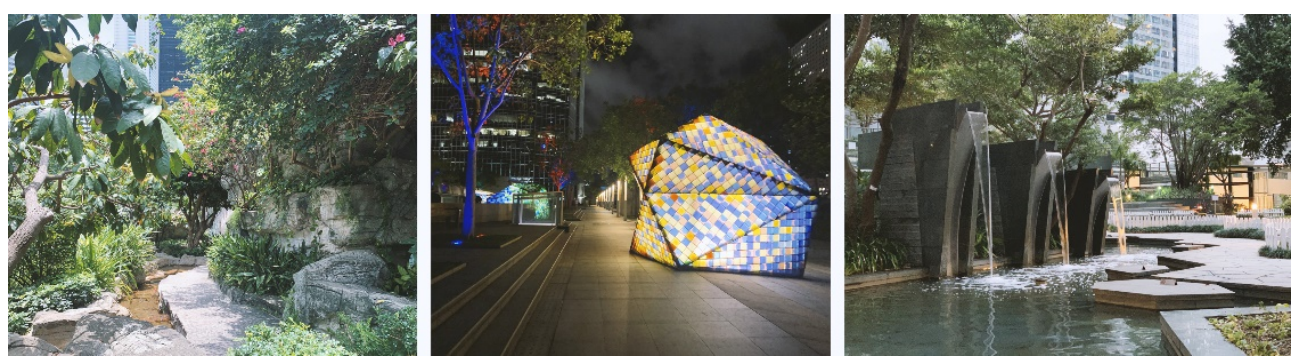

Figure 7 Cheung Kong Park (left) Hong Kong Station Development (middle) and Kowloon Station Development (right)

\section{No commercialisation}

Except for Kowloon Station Development mentioned above, the other cases in Cluster 3 demonstrates no sign of commercialisation. The primary function of the developments is, for most cases, residential building, such as Prosperous Garden, Jubilant Place, The Avenue 5F Roof Garden.

\section{Lengthy Regulations}

Contrary to the long-held presumption that public spaces are free to use, all POSPD in Cluster 3 posted lengthy, daunting and subjective regulations. Besides basic rules such as "no littering," "no smoking," eating and drinking are not allowed in Cheung Kong Park (Figure 8). Other subjective judgments, including "prohibitions of obscene language," are also included in the regulation. Similarly, the same 21 regulations are listed in Hong Kong Station Development and Kowloon Station Development. As discussed before, the excessive control over POS users may give a false sense of safety or the impression of a space being inaccessible to accidental users, further deteriorate the publicness of a space (Pearsall et al., 2020). This characteristic of Cluster 3 makes it "pseudo-public."

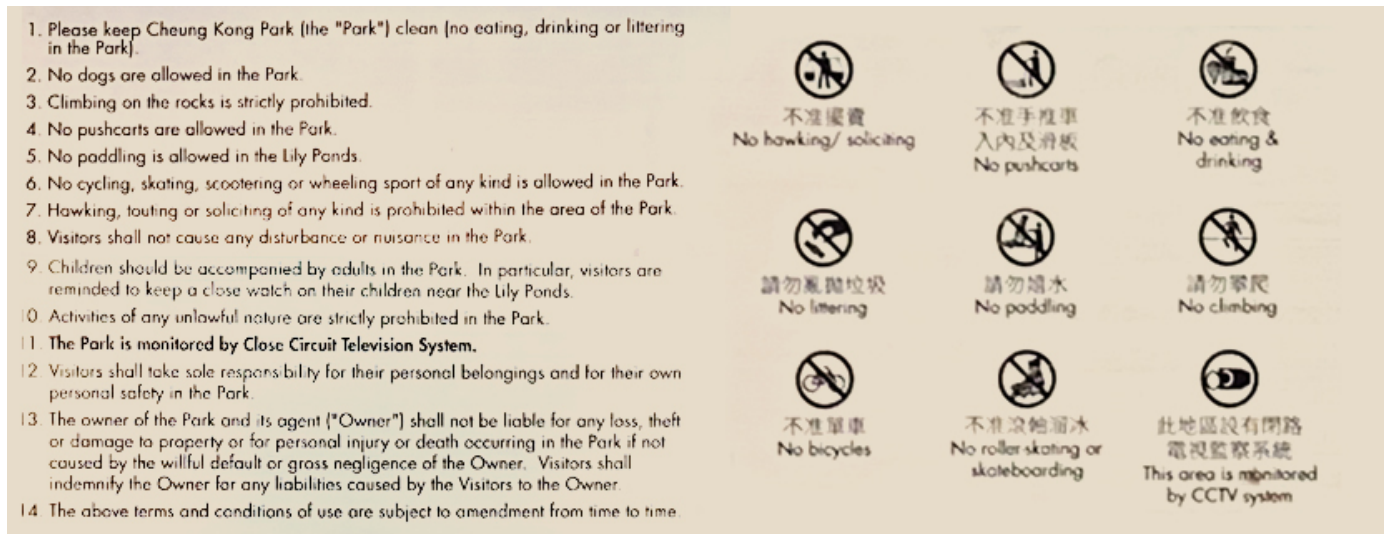

Figure 8 Regulations of Cheung Kong Park

\section{Cluster 4, "Consumers' paradise"}

\section{Commercialisation}

Cluster 4 has the fewest number of POSPD. For the seven cases, "Commercialisation" is the most prominent character. Shops, bars and food vendors wrap around the POSPD. Sometimes, the café shops place tables and chairs on the plaza, creating a vague atmosphere between public and private. Theme events and programmes that encourage use are held regularly to attract potential users beyond their instant neighbourhood. The characteristics of these POSPD are interpreted by the advertisements hang on the walls of the buildings, intended to turn more POS users into consumers (Figure 9). These POSPD 
provide well-maintained features and recreational chances that are suitable for different age groups. However, they have limited contributions to facilitating social interaction since most of them do not encourage other activities beyond shopping.
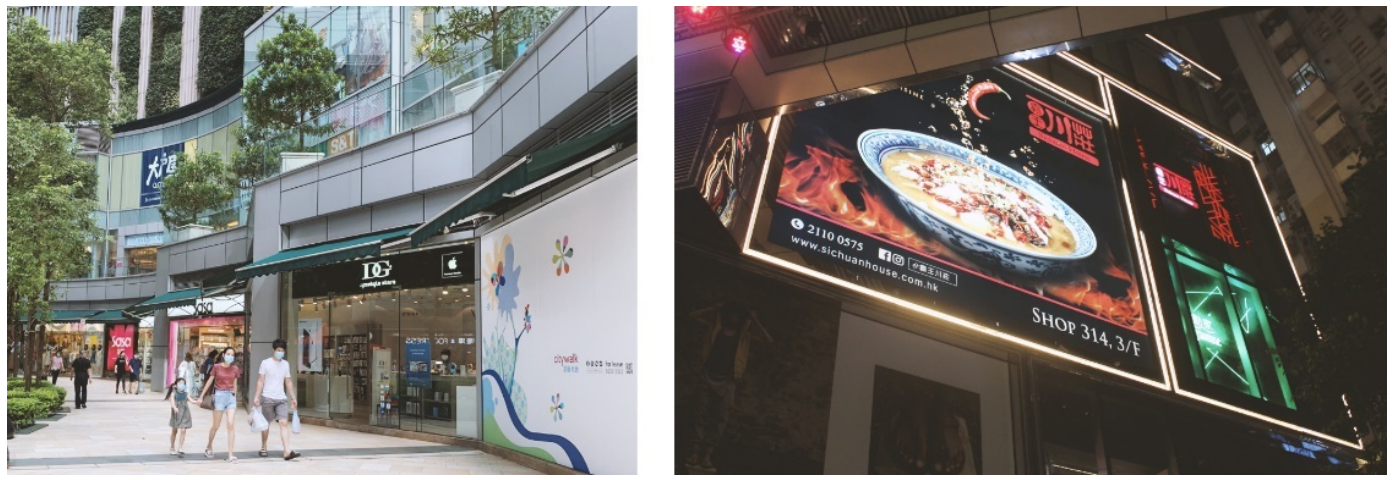

Figure 9 Ubiquitous advertisements (left: Vision City; right: K11 Art Mall)

\title{
Highly Accessible
}

These POSPD received high scores for accessibility for locating in highly visible, easily accessible locations. Besides these shopping malls they attached to are well-known and easy to reach, their precise locations are usually clearly pinpointed on a map to lead the citizens.

\section{Round-the-clock}

Except for the POSPD in Vision City which is open every day from 6:30 a.m. to 11:00 p.m., which has already covered the time period when people prefer to enjoy POS, other POSPD in Cluster 4 are all open 24 hours. These commercial spaces offer recreational spaces that are animated during different times of the day.

\section{Guarded}

With C4-1 are guarded by long-listed, subjective rules and regulations; C4-2 leave more freedom to the users. But overall, these commercialised spaces are highly controlled by security cameras and private surveillance. Security personnel are visibly at work in these POSPD (Figure 10). Despite these POSPD are beautifully designed, the presence of cameras and private security, to some extent, shape the overall performance in terms of publicness and management. "Good spatial design" and "heavy surveillance" are also keywords used to describe cases in Cluster 3.
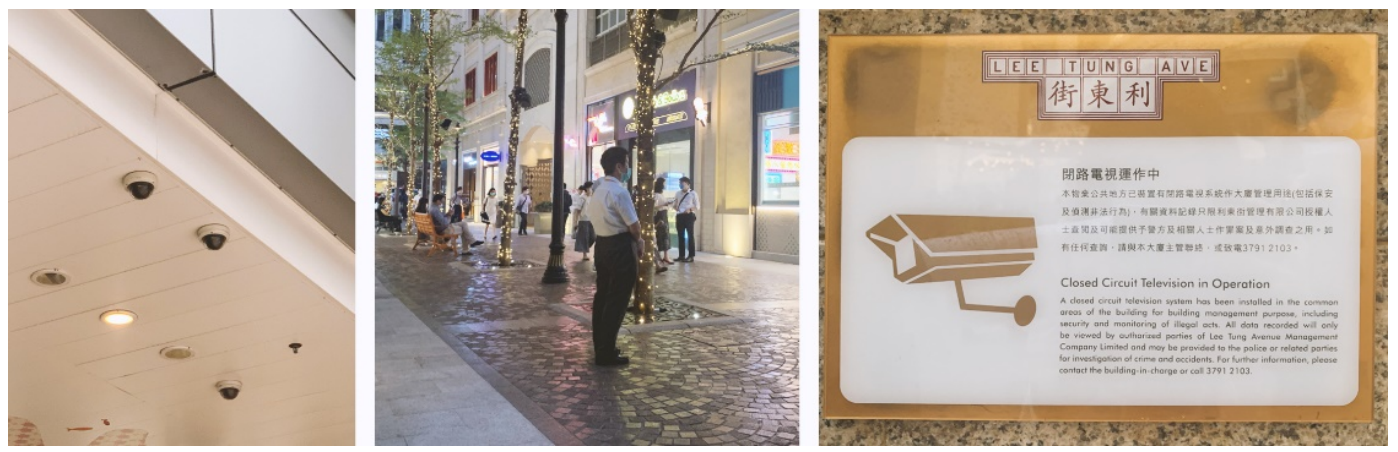

Figure 10 CCTV and security guard

\author{
Cluster 5, "Public Plaza”
}

Basic rules 
Cluster 5 is the largest group with 18 spaces included. Despite that POSPD in this group all have posted rules, these rules are quite basic such as "no smoking" and "Do not pick flowers." Subjective regulations that constrain individuals' behaviours according to personal evaluations are broadly absent (Figure 11). Very few of them have security personnel on sites. The Filipino domestic helpers usually occupy these spaces during public holidays to meet friends and relax.
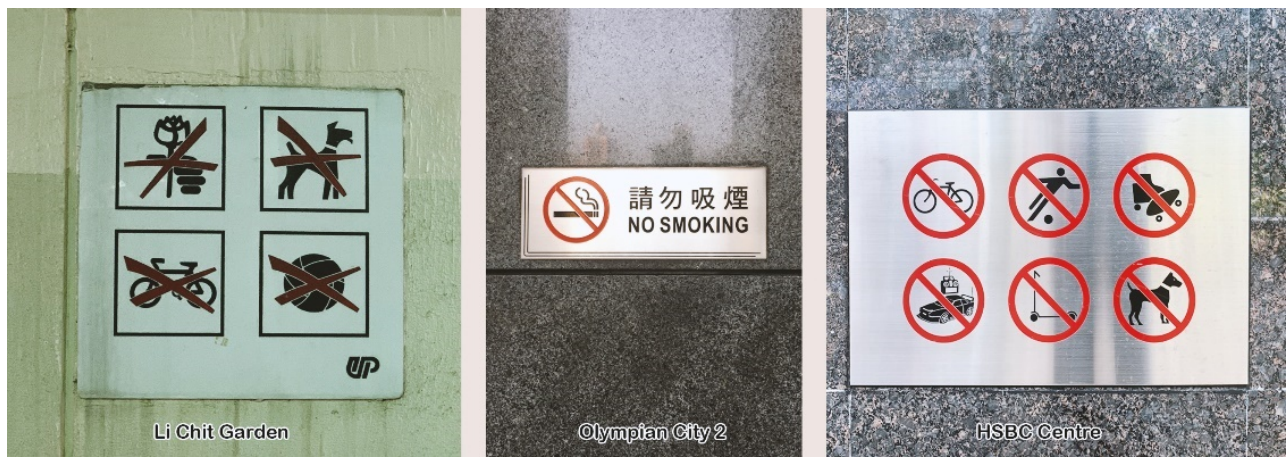

Figure 11 Basic rules posted in Li Chit Garden (left), Olympia City (middle) and HSCB Centre (right)

\section{Round-the-clock}

The majority of POSPD cases in this cluster open 24 hours a day, seven days per week, others' open hours also covers the normal POS usage time.

\section{No commercialisation}

Compared to Cluster 4, there is no tangible evidence of commercialisation for Cluster 5. Some spaces are physically located adjacent industrial zone (e.g., $\mathrm{H}$ Cube and Indi Home) or along busy transportation routes (e.g., Trinity Tower), and are broadly not as of high quality and patronage than POSPD in Cluster 4.

\section{Privileged accessibility}

The general patronage rate observed during the field survey suggests that some POSPD are created for specific populations instead of the general public. None of the POSPD in Cluster 5 has a readily accessible restroom, but since the primary use of these projects are residence or office, these POSPD are intentionally designed to serve residents (or workers) that live (or work) in close proximity. As thus, providing a restroom may be considered unnecessary. Pearsall et al. (2020) revealed a similar phenomenon in gentrified neighbourhoods.

For example, Olympia Park, which is attached to Olympia City One, is an expensive community in Yau Tsim Mong District. Compared to other POSPD, the quality of decorations and details in Olympia Park is excellent. The space provides discrete areas for various ages to play and relax (Figure 12). No-trespassing signs are only posted on the walls of their private property. However, on the one hand, the space is somehow gated, located at the podium level. It can only be reached through the Olympia MTR station, or taking the elevator. These characteristics do mislead the general public to regard it as a private garden and channel funds to amenities that do not serve the public fairly, creating a "privileged accessibility" as a consequence. 

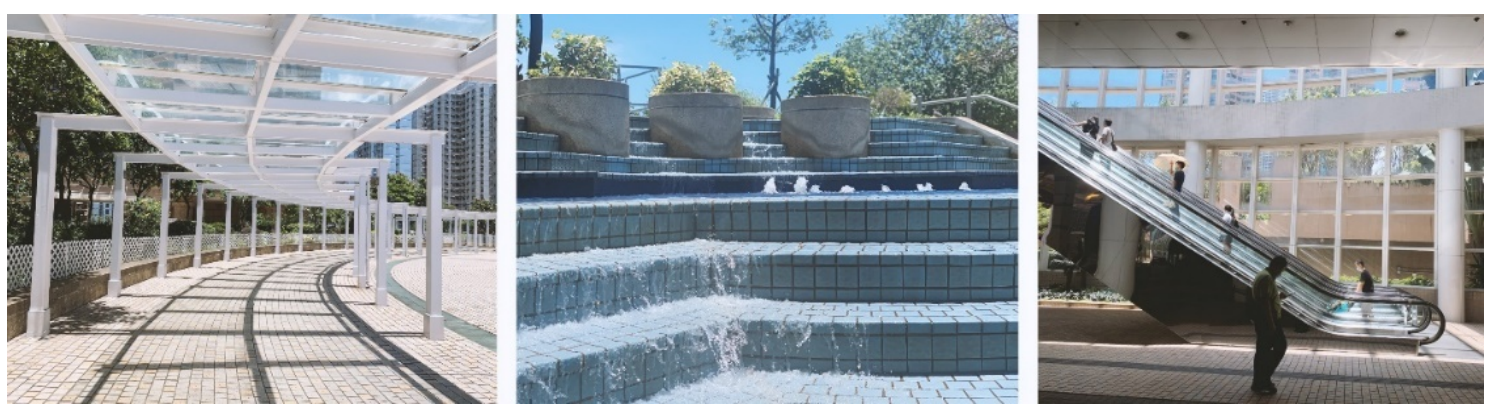

Figure 12 POSPD of Olympia City

\section{Conclusion}

Back to 25 years ago, Cuthbert (1995) warned that, given the fact that lands became increasingly expensive for the government to accommodate its scanty standards for open space, there emerged a growing trend towards involving private sectors into the POS provision process. Control and surveillance in these privatised POS that occur as a result of this close cooperation result in an increasingly complex POSPD typology and require more sophisticated investigation to capture the specificity of each type.

While numerous studies have made their attempts to examine POS typology from different perspectives, the main target of this section is to propose a typology of the new form of privatized public spaces in terms of their publicness and management. The empirical evidence available thus far indicates a typology that contains five POSPD types: (1) "Edge Zone" (12/66); (2) "Hide-and-seek" (15/66); (3) "Pseudo-Public space" (14/66); (4) “Consumer's Paradise" (7/66); (5) "Public Plaza” (18/66).

The typology result confirms the previous claims that POPSD managed by large commercial corporations, and POSPD developed in large residential projects are usually of good quality, facilities are well maintained. Yet, their design features and management approaches show a propensity for serving the customers and residents instead of the general public. Both of them create a privileged accessibility that brings about the exclusion of certain individuals or groups who do not fit their desire. By contrast, for those types that have no access restrictions, the space location or quality is often dissatisfactory. People either have difficulties in acknowledging their existence as a public space or tend not to use it because of their poor quality.

In an era of privatisation, the new typology contributes to the debate concerning the situation of POSPD in Hong Kong in terms of publicness and management. It draws attention to the great potential for improving the spatial justice performance of different types of POPSD by addressing the corresponding weakness and shortcomings. Mantey and Kępkowicz (2018) once delineated the "civic control" as the most desirable form of POS management. It refers to showing respect to general rules and involving the citizens in the control process. This is the desired scenario we advocate to maintain the space at a comfortable level and reject unwanted behaviours. Policy makers are suggested to take actions to help protect the intermingling of social groups, raise regulatory requirements to the private developers to maintain the POSPD properly. People, as well as the private sectors' rights and obligations need to be officially recognized to tilt the balance of power a bit toward the general public, instead of demonstrating coercive powers during the management. Through which, disagrees and disputes among different stakeholders could be potentially settled. 


\section{References}

AKKAR, Z. M. 2005. Questioning the" publicness" of public spaces in postindustrial cities. Traditional Dwellings and Settlements Review, 75-91.

CARMONA, M. 2010. Contemporary public space: Critique and classification, part one: Critique. Journal of urban design, 15, 123-148.

CUTHBERT, A. R. 1995. The right to the city: surveillance, private interest and the public domain in Hong Kong. Cities, 12, 293-310.

DE MAGALHÃES, C. 2010. Public space and the contracting-out of publicness: A framework for analysis. Journal of Urban Design, 15, 559-574.

HO, D. C., LAI, L. W. \& WANG, A. 2020. The effects of 'publicness' and quality of publicly accessible open space upon user satisfaction. Environment and Planning B: Urban Analytics and City Science, 2399808320903733.

INITIATIVE, H. K. P. S. 2018. privately owned public space audit report. Hong Kong.

JIAN, I. Y., CHAN, E. H., YAO, T. Y. P. J. B. E. P. \& MANAGEMENT, A. 2020a. ICT as a solution for the revitalization of public open space in private developments.

JIAN, I. Y., LUO, J. \& CHAN, E. H. 2020b. Spatial justice in public open space planning: Accessibility and inclusivity. Habitat International, 102122.

KOHN, M. 2004. Brave new neighborhoods: The privatization of public space, Psychology Press.

MANTEY, D. \& KĘPKOWICZ, A. 2018. Types of public spaces: The polish contribution to the discussion of suburban public space. The Professional Geographer, 70, 633-654.

MINGZI, C. 2019. A private garden on the 6,400-metre rooftop of Kwai Fong Station?

NÉMETH, J. \& SCHMIDT, S. 2007. Toward a methodology for measuring the security of publicly accessible spaces. Journal of the American Planning Association, 73, 283-297.

NÉMETH, J. \& SCHMIDT, S. 2011. The privatization of public space: modeling and measuring publicness. Environment Planning B: Planning Design, 38, 5-23.

PEARSALL, H., ELLER, J. K. J. L. \& PLANNING, U. 2020. Locating the green space paradox: A study of gentrification and public green space accessibility in Philadelphia, Pennsylvania. 195, 103708.

ROSSINI, F. \& YIU, M. H.-L. 2020. Public open spaces in private developments in Hong Kong: new spaces for social activities? Journal of Urbanism: International Research on Placemaking Urban Sustainability, 125.

SCHMIDT, S., NEMETH, J. \& BOTSFORD, E. 2011. The evolution of privately owned public spaces in New York City. Urban Design International, 16, 270-284.

VARNA, G. \& TIESDELL, S. J. J. O. U. D. 2010. Assessing the publicness of public space: The star model of publicness. 15, 575-598.

WANG, Y. \& CHEN, J. 2018. Does the rise of pseudo-public spaces lead to the 'end of public space'in large Chinese cities? Evidence from Shanghai and Chongqing. Urban Design International, 23, 215-235.

YOUNG, I. M. 1990. Justice and the Politics of Difference, Oxford, Princeton University Press. 